\title{
Reflexiones metapoéticas en esbozos inéditos de Miguel Hernández
}

\author{
Carmen AlEmAnY BAY \\ Universidad de Alicante \\ ORCID: 0000-0002-I405-9359
}

\begin{abstract}
En las presentes páginas trataremos de analizar una serie de reflexiones metapoéticas que se encuentran entre borradores, todavía inéditos, de Miguel Hernández. Las observaciones sobre el hecho poético se circunscriben a dos etapas. La primera, correspondiente al ciclo de Perito en lunas, y la tercera, que responde al ciclo de la guerra; coincidiendo temporalmente con las reflexiones que de este tipo ya se conocen del poeta. Los razonamientos metapoéticos inéditos, escritos durante la guerra, son menos abundantes y vienen a corroborar lo que de este ciclo sobre el tema ya conocemos. A estas consideraciones de carácter metapoético, se unen otras que remiten a escritores referentes.
\end{abstract}

Keywords: Miguel Hernández, metapoesía, inéditos, esbozos, proceso de creación.

\section{Palabras introductorias}

En el III Congreso Internacional sobre Miguel Hernández, que se celebró con motivo del centenario de su nacimiento, dábamos a conocer la existencia de un buen número de textos inéditos hernandianos que correspondían a borradores y bocetos de poemas. Tal como decíamos en la publicación de esta ponencia, que titulamos «Notas y reflexiones sobre textos, aún inéditos, de Miguel Hernández»,

estos textos, si bien no son esenciales sí creo que son fundamentales. En primer lugar porque el propio poeta los conservó como parte también de su obra [...] En segundo lugar porque estos manuscritos nos hacen abundar en la idea ya esbozada de la intensidad con que Miguel Hernández elaboró su poesía y su creencia de que el poema era un objeto que había que construir y un ejercicio de reflexión, en definitiva, hacer de la escritura poética un oficio (Alemany 20I2: 2I5).

De la totalidad de los manuscritos, un centenar pertenecían al primer ciclo, al de Perito en lunas; una veintena al segundo -escritos probablemente entre finales de 1934 y hasta la primavera de I936-; una treintena al período bélico y casi una veintena al último, perteneciente al Cancionero y romancero de ausencias (216). Adelantamos que en este corpus no existe ningún texto extenso en el que haya una reflexión sobre la poesía, sino que se trata de 
frases o textos breves que el poeta fue intercalando entre sus borradores y de cuyas características hablaremos en líneas ulteriores.

Como punto de partida diremos que estas observaciones sobre lo poético se centran, fundamentalmente, en el primer período y alguna que otra reflexión de esta índole durante la guerra; lo cual coincide, temporalmente, con las consideraciones metapoéticas hernandianas ya editadas. No son abundantes los trabajos que se han publicado sobre las ideas teórico-literarias de Miguel Hernández, lo cual tiene su lógica dado que no estamos ante un teórico; aunque sí debemos señalar que, con frecuencia, la crítica hernandiana hace referencia a ellas. Agustín Sánchez Vidal, en su «Introducción» a las «Prosas» de la Obra completa de Miguel Hernández, comenzaba con estas palabras: «Las prosas de Miguel Hernández nos muestran a menudo aspectos relativamente inéditos de su personalidad artística, y en algunos casos hacen pensar en un narrador con muy serias posibilidades» (I992: 2049). Pedro Aullón de Haro publicó, en I993', un año después del cincuentenario de la muerte del poeta de Orihuela, un artículo que se abre con las siguientes palabras: «Miguel Hernández no fue, ciertamente, un pensador (ni tuvo tiempo de serlo), al menos en el sentido fuerte que define a aquellos artistas creadores a un tiempo de un corpus teórico o de alguna doctrina relevante acerca de qué es o cómo se construye o debiera construirse el Arte» (1993: 259), para explicar a continuación que ello no es óbice para que sí tenga "pensamiento programático» y «una específica y clara conciencia de su trabajo literario; todo gran poeta en realidad las tiene» (259). Y el primer párrafo finaliza con las siguientes palabras: «Se comprobará que Hernández, como teórico, fue inteligente y estuvo dotado de finura» (259). Aullón habla, asimismo, de la brevedad de estos textos y su escaso número: desde su poema "Poesía», pasando por sus reflexiones en prosa - Mi concepto de poema» y la segunda de las tres partes que componen «Fórmulas», subtitulada «(De poesía)»-, algunos otros poemas como «Mary Dios», «Niebla- Dios y poema» y «Mar- profundo y superficial». O las reseñas «Pablo Neruda, poeta del amor» o «Residencia en la Tierra», publicada esta última en el periódico El Sol a comienzos de 1936.

De ahí se desemboca finalmente en el período de la guerra en el que podemos encontrar diversas manifestaciones, fundamentalmente en los textos en prosa escritos en esta etapa; y a estas se suma el «Prólogo» del Teatro en la guerra que sería, al decir de Aullón, «su última declaración programática extensa, esta vez destinada a resumir la razón experiencial de su punto de vista y proclamar la efectividad del teatro breve reiterando su idea literaria de "arma de guerra"» (268). Ha sido Juan Cano Ballesta el que con más inten-

I Tres años después, Aullón publicará otro artículo, «La teoría explícita de Miguel Hernández» (1996: 8I-84), en donde aborda dos de los seis núcleos que expuso en el texto originario, pero no se aportan nuevos argumentos. 
sidad ha investigado y trabajado la metapoética hernandiana en tiempo de guerra; y a esas investigaciones haremos alusión a lo largo de estas páginas.

\section{Sobre los manuscritos hernandianos}

Entre el ingente material, provisto fundamentalmente de largas tiradas de oraciones que Miguel Hernández separaba entre guiones, encontramos algunas frases que se concentran en pensamientos poéticos. Este sistemático proceso de creación empezó tras su primer viaje a Madrid. Su posicionamiento radical en el aprendizaje poético le llevó a trabajar intensamente el lenguaje, a copiar definiciones de palabras, a escribir juegos de rimas que extraía de diccionarios, con la finalidad de ir aumentando su exiguo caudal lingüístico y con la intencionalidad de ir creando un vocabulario propio. A partir de esas copias, configuraba series continuadas de versos que separaba entre guiones y que le servían como referente para escribir poemas (Alemany 20I3: I5-27).

\section{Reflexiones inéditas sobre la poesía}

\section{Reflexiones metapoéticas en el primer ciclo hernandiano}

Sabemos que el autor de Perito en lunas no fue, ni pretendió ser, un teórico de la poesía, ni siquiera abundan entre sus composiciones las artes poéticas, ya lo hemos comentado; pero sí tuvo como escritor una lógica preocupación por desentrañar la esencia de lo poético. El caso más paradigmático es su prosa «Mi concepto de poema» y algunos versos del ciclo que abundan sobre la teorización de lo poético. Dentro de este ciclo, y entre los materiales inéditos que reflexionan sobre la escritura, podríamos distinguir dos momentos diferentes: el que se correspondería con la elaboración de su primer libro poético; y un segundo que coincide temporalmente con la gestación del «Primitivo silbo vulnerado».

Tal como advertimos en nuestra publicación, «no sabíamos de su interés por algo tan esencial, fundamentalmente en la poesía del siglo xx, como la importancia y la trascendencia de la imagen en el poema» (Alemany 20I2: 2I6). En varias ocasiones, y entre listados de metáforas, greguerías e ideas, reflexiona sobre la importancia de esta en su proceso de escritura: «no me deja estar la imagen hasta que no la escribo» (L-38) ${ }^{2}$. El poeta manifiesta en estas palabras la obsesión por la escritura, la voluntad de que los emble-

2 Entre paréntesis anotamos la referencia que corresponde al manuscrito. La primera catalogación fue realizada por José Carlos Rovira y por mí, y es la que fue utilizada en la Obra completa. 
mas mentales, como lo es la imagen, permanezcan, se queden en la mente del lector. No olvidemos que para el imaginismo la búsqueda de la imagen debía basarse en la exactitud; por ello, no es extraño que nuestro poeta dedicase largo tiempo a escribir una y otra vez posibles imágenes para sus poemas. Sintomática a este respecto es esta definición que de ella nos ofrece: «la imagen sea: no una ilustración del verso, sino una ilustración de sí misma, de todo el poema (el poema una continua imagen) de toda la poesía» (219/C- 25...37). De esta manera, Hernández parece reducir básicamente toda la poesía a la imagen, ella es la esencia. De ahí que las composiciones de esta etapa, las octavas de Perito en lunas y las de este libro excluidas, como también las décimas que al mismo tiempo que las octavas escribiera, sean un haz de imágenes que nos remiten a un objeto determinado. Muy lejos está Miguel Hernández de los poemas que publicara en algunos periódicos o revistas en Alicante y Orihuela antes de emprender su primer viaje a Madrid, y también de aquellas composiciones escritas a plumilla en un libro de cuentas y que se llevara a la capital para mostrarlas a los poetas del 27, que no llegó a conocer en este viaje. Poemas sustanciados por el yo romántico, versos cargados de influencias clásicas que desaparecerán con la escritura de Perito en lunas.

En uno de los manuscritos apuntará: «el mar resulta bello a fuerza de darle vueltas como a mis mejores imágenes» (219/C-25...37); frases en las que subyace la voluntad de reducir estas a sus propias dimensiones poéticas y que, como debe de ser, la imagen resulte evocadora a fin de afianzar su perdurabilidad. Tal como afirmábamos en nuestra publicación, hay que resaltar en Hernández la importancia que le dio a «la visualización del poema de la que ya Horacio hablara en su máxima ut pictura poiesis» (Alemany 2012: 2I6).

Otra reflexión, que creemos resulta de mucho interés, es la que sigue: «el caos del poema: I el estado de formación- la nebulosa, la arquitectura, la forma, el lucero del poema» (416/Z-26...56). De forma tácita, nuestro poeta está declarando cuál es su proceso creativo, cómo él estaba construyendo sus composiciones: «el estado de formación», que en su caso enlaza con los esbozos; «la nebulosa», las ideas con las que se va construyendo el poema, los versos que va tachando hasta llegar a «la arquitectura»; una arquitectura que se traduce en octavas, en décimas o en estrofas rimadas. Son esas las composiciones que Hernández está escribiendo en estos tiempos, pues todavía no ha llegado al verso libre que aparecerá en su escritura a partir de su estrecha relación con Pablo Neruda y Vicente Aleixandre. Hablamos de formas poéticas que requieren de todo un entramado arquitectónico como paso previo a «la forma», a esa construcción minuciosa del encaje en el que las sílabas se van colocando, tal como requiera la estrofa elegida. Una forma 
adecuada, la perfecta, con el fin de llegar a «el lucero del poema»; sin duda, una hermosa metaforización para designar el producto final.

Sigamos sumando pensamientos metapoéticos: «poesía: geometría celestial, arquitectura hablada» (4I6/Z-26...56). Este enlazaría con lo que hemos apuntado anteriormente, con la idea de la perfección como camino para lograr el mejor de los poemas. Sin embargo, tanto esta como las que anotaremos en líneas posteriores pertenecerían concretamente a una idea de poesía enmarcada en las composiciones incluidas en el «Primitivo silbo vulnerado», como lo son «Mar- y Dios», «Niebla- Dios y poema» y «Marprofundo y superficial»; poemas que, según Aullón de Haro, «presentan sustancialmente una simbolización esencialista extendida, sobre todo, en torno a las atingencias trascendentalistas entre Dios, Mar y Poema o Poesía, y, asimismo, relativas a la relación conceptista de escondimiento, secreto o enigma y verdad o superficie» (I993: 263).

La creación de lo divino, como arquitectura, o la misma designación genésica de que la palabra había que designarla, aparece en un texto que se nos antoja esencial. El poeta, como veremos a continuación, escribe un esbozo con una serie de ideas que van a desembocar en unos versos inacabados e inéditos. Es interesante este proceso, frecuente en aquellos días de febril escritura. El poeta parte de la composición de un esbozo y, a partir de lo allí esgrimido, construye versos que, finalmente, no tendrán continuidad, ya que esa última línea parece indicarnos que se rompe la composición del poema para continuar con una frase que, asimismo, será interrumpida:
premundo- la luna de pronto fue luna llena- el árbol primero no tuvo in- fancias fue árbol cuando Dios quiso en toda la extensión de la palabra- ordenación de imágenes- Dios, yo y el ciego creamos el mundo a nuestra imagen y semejanza- crear por recrear y recrearnos ${ }^{3}$ - la creación es función divina- todo el que siembra algo es algo dios- logro- Dios estaba en amor- soledad general de Dios, particular y mía-Harto de abismo- orden- la luz y la tiniebla y no solo más Dios estaba en amor, como hay que estarlo
para hacer: sin quehaceres
Y ser eterno y Harto
Y ser azul Perenne.
Y pondrás su mejor obra: Su nada, la soledad vacía de redonda compaña de geometría viva.
la palabra nació con los objetos, había que designarla (2I4/C-I2).

3 Las palabras que aparecen en cursiva se corresponden con las que Miguel Hernández tachó en el manuscrito. 
En este pensamiento poético hay un principio del que irradia todo lo demás: «la creación es función divina»; y también todo aquel que crea tiene algo de Dios, o de pequeño Dios -como diría el chileno Vicente Huidobro-, tal como podemos recoger en la siguiente frase: «Dios, yo y el ciego creamos el mundo a nuestra imagen y semejanza». Estos razonamientos nos llevan a una composición, incluida también en el "Primitivo silbo vulnerado», «CIEGO-espiritual»; poema al que la crítica no ha prestado demasiada atención y que creemos es también una composición dotada de claros contenidos metapoéticos. Extraemos algunos versos que nos conectan con el citado esbozo: «¿Para qué? La presencia; ya te basta / la esencia de las cosas: / ellas te dan sus nombres, tú las cargas / de condición y forma» (Hernández I992: 425, vv. 9-I2), y mucho más clarificadores serán los siguientes: «Dios ha creado el mundo; tú lo vuelves / a crear a tu imagen» (vv. I5-I6). Reflexiones que si bien no aportan nada novedoso en lo teórico, sí abundan en las ideas que el poeta estaba manejando en aquellos momentos sobre la esencia de la escritura. Y en ella también caben exhortaciones que nos remiten a referencias sexuales muy presentes en aquellas composiciones que Miguel Hernández escribiera entre Perito en lunas y El rayo que no cesa: «mi poesía, la sustancia divina de mi sexo» (334/X-I33...I37).

Regresemos al texto que transcribimos en líneas anteriores, llamativa nos parece la referencia a la soledad como algo intrínseco a la escritura. En los poemas del «Primitivo silbo vulnerado», el término aparece con cierta frecuencia; en la ya citada composición, «CIEGO-espiritual», leemos estos versos que abren el poema: «Revelación del mundo no has tenido, / noche oscura del cuerpo» (Hernández I992: 425, vv. I-2). Y del poema que a esta le sigue en la Obra completa, "CIGARRA-excesiva», se desprenden estos versos: «la soledad, sonora / torna tempestuosamente ahora» (426, vv. 4-5). En el borrador leemos «soledad vacía», y no la «soledad sonora» que San Juan de la Cruz inmortalizara en su Cántico espiritual (I622); ni aquella que Juan Ramón Jiménez sustanciara en los versos de su libro La soledad sonora (I908). Miguel Hernández, quien a esas alturas ya había leído con intensidad a ambos poetas, cambia la adjetivación para ofrecernos nuevas sugerencias que las imágenes poéticas puedan provocar. La idea de la «soledad» aparece siempre imantada a la escritura, sea «vacía» o sea «sonora»; una «soledad sonora» que resuena en otros manuscritos de entre los borradores no publicados: «la soledad sonora de la membrada mies yo ya tengo preparadas, el cuerpo para el verano» (334/X-133...I37). En otro manuscrito, vuelve a reincidir sobre esta idea: «sabiendo que he de perder juego, soledad- mi soledad preñada de inminentes peligros de compaña» (L-I3); texto al que le sigue la siguiente frase: «batalla de muerte en campos de plumas», que nos remite directamente al verso gongorino «a batallas de amor, campos de plumas». Nuevamente, el poeta se acoge a referencias literarias sumamente estratifi- 
cadas en el imaginario para sustituir un término por otro con el fin de intentar nuevas significaciones, nuevas sugerencias poéticas.

Al hilo de lo que acabamos de anotar, en estos borradores todavía inéditos aparecen algunas referencias literarias que nos remiten a las lecturas atentas que Miguel Hernández hiciera en aquella etapa. Nos vamos encontrando, entre estos múltiples manuscritos, alusiones cervantinas como «velones perolas a lo yelmo de mambrino» (4I6/Z-26...56); o la referencia bíblica «más difícil que escaparse por el ojo de una aguja» (219/C-25...37), frase misma que aparecerá en un boceto perteneciente al segundo ciclo, al del amor, en la carpeta (342/X-I45). En aquella misma carpeta (219/C-25...37) hallamos la frase «el mar tabla de salvación de la tierra» que nos remite al conocido tópico literario, que el mismo Hernández atenderá poéticamente en $\mathrm{El}$ rayo que no cesa, «el amor como tabla de salvación». El poeta sigue con esos juegos literarios que procuran nuevas significaciones, e interesantes son a este respecto las referencias a Francisco de Quevedo cuando anota: «un pie lacónico tengo (Quevedo) mentirosa la cara de pintura-» (338/X-I4I), y «pero qué digo amor, si no tengo (para la vida de Quevedo)» (323/X-94), lo que nos induce a pensar que algo en concreto sobre el gran poeta del Siglo de Oro quisiera escribir el de Orihuela.

No falta la referencia a su amigo Ramón Sijé entre sus esbozos, a ese que fue uno de sus principales maestros -a pesar de la escasa diferencia en edad, pero sí en formación-, y queremos insistir en este punto en que las ideas poéticas que está creando Miguel Hernández en aquellos días, que oscilan entre I933 y comienzos del I934, vienen directamente de la influencia del que tan crucial fuera en la formación hernandiana: «A mi amigo, Ramón Sijé, combatiéndolo porque dice que quien canta amor no ama, un aire puro de fogoso frío que apaga cirios y me prende el alma» (219/C-25...37). Palabras que podríamos considerar como una antesala de los poemas que comenzará a escribir Miguel Hernández sobre el amor y que desembocarán en El rayo que no cesa, previo paso por El silbo vulnerado e Imagen de tu huella; aunque todavía las reminiscencias un tanto místicas se apoderan de esta reflexión. Y entre los manuscritos nos asalta la frase, «atento a la muerte y desatento a la vida» (219/C-25 ...37), que nos remite a un par de versos de su famosa «Elegía»: «No perdono a la muerte enamorada, / no perdono a la vida desatenta» (Hernández I992: 5IO).

Y para concluir con las presencias metapoéticas hernandianas de esta primera etapa, nos faltaría añadir otras frases que retratan y amplían su visión sobre el hecho poético: "ya no falsificarás sensaciones, poeta» (343/X-I46). Y otra, de índole más genérica, como lo es: «de una sin satisfacción sale un poema, un mundo» (L-28); mundos que está creando a partir de las muchas frustraciones que está sufriendo Miguel Hernández, como lo fue el darse cuenta tras su vuelta de Madrid de que, si quería ser un verdadero poeta, tenía que empeñarse en trabajar las palabras y el verso al máximo; tras darse cuenta en 
la capital de su deficiente formación y de que el único camino para conseguir crear versos verdaderos era el trabajo ingente sobre el texto.

\section{Reflexiones metapoéticas del tercer ciclo hernandiano}

Como advertíamos al comienzo de estas páginas, ha sido Juan Cano Ballesta quien con más intensidad se ha dedicado y rescatado documentos que fueron publicados por él y por Robert Marrast en Poesía y prosa de guerra y otros textos olvidados (1977). A partir de entonces, Cano Ballesta publicará artículos fundamentales sobre el presente asunto, entre los que destacamos: «Miguel Hernández: la reflexión del poeta sobre el arte y la guerra» (I996) y «Miguel Hernández y el debate cultural de los años treinta (El poeta ante el Guernica)» (2004)4 . Con anterioridad, en las Actas del I Congreso Internacional dedicado a Miguel Hernández, que tuvo lugar en 1992, nuestro crítico -en el epígrafe «Meditación teórica sobre el arte» (I993: I33-I36), incluido en «Miguel Hernández periodista en el frente y narrador épico»- recalaba en tres prosas relacionadas con el tema y publicadas con antelación por él mismo y Robert Marrast en el libro ya citado; textos que durante la guerra vieron la luz en revistas del frente: «Sobre la toma de la Cabeza: carta y aclaración» (Hernández I992: 22I6), «Hay que ascender las artes hacia donde ordena la guerra» (Hernández I992: 2235) y «[La poesía "como un arma”]» (Hernández I992: 2227). Se trata de tres escritos neurálgicos para entender la visión hernandiana del arte en los tiempos de guerra.

De entre los manuscritos nos encontramos con las siguientes frases: «el poeta es, soy el hombre más herido en medio de su pueblo y la lucha y puede ser también el más muerto- pongo mi alma a disposición del pueblo» (38I/XI9I). Estas palabras nos remiten a su poemario Viento del pueblo, en primera instancia; pero fundamentalmente al contenido de «[La poesía "como un arma"]», y de manera directa a las frases que cierran esta reflexión: «Vivo para exaltar los valores puros del pueblo, y a su lado estoy tan dispuesto a vivir como a morir» (Hernández I992: 2227).

Menos personal, pero más incisivo, se mostrará en el siguiente texto en el que hace una dura crítica a aquellos que privilegian la estética a pesar de ser artistas comprometidos; asimismo, opinará sobre el momento en el que mejor se pueden representar algunas manifestaciones artísticas: «Los pintores de hoy temen a la pintura, la rehúyen: Picasso es un ejemplo-El cine es a la hora de los sueños cuando mejor se da, el teatro debe ser representado a la luz del día, a pleno sol» (384/X-I89) (20I2: 222)5. Estas frases se nos antojan

\footnotetext{
4 Véase también al respecto el artículo de Manuel Aznar Soler, «Miguel Hernández: ética y estética del comunismo» (I996).

5 Juan Cano Ballesta dio a conocer parcialmente este documento que le enseñó Josefina Manresa, viuda de Miguel Hernández, en 1985, y que recoge en «Miguel Hernández y el debate cultural de los años treinta (El poeta ante el Guernica)».
} 
sumamente interesantes; si bien no aluden a la poesía, sí a las artes visuales. En la primera, la referente a la pintura, Hernández es más que explícito al sacar a colación a Pablo Picasso; y añadimos, por su obra el Guernica. Por lo ahí dicho, se hace necesario remitirnos a «Hay que ascender las artes hacia donde ordena la guerra», que publicara en Nuestra Bandera (2I/II/I937), y del que transcribimos el siguiente párrafo, pues incide en la idea que en el esbozo resume:

Los hombres de la pintura, la escultura, la poesía, las artes en general, se ven hoy en España impelidos hacia la realización de una obra profundamente humana que no han comenzado a realizar todavía. Yo veo a los pintores, a los escultores, los poetas de España empeñados en una labor de fáciles resoluciones, sin el reflejo mejor de los problemas que la situación de este tiempo ha planteado. Advierto a estos hombres llenos de una frivolidad artística heredada de otros hombres, artistas de relumbrón, excéntricos en pintura, escultura, poesía, arte en general. Veo que los pintores temen a la pintura, la rehúyen y se entregan a juegos ya en desuso del cubismo y sus provocadores (Hernández 1992: 2235).

Llama la atención que en el texto publicado el nombre de Picasso no aparece; pero habla de cubismo, que era una manera de aludir a Picasso y a su Guernica sin necesidad de decir su nombre ${ }^{6}$. Asimismo, como se puede comprobar, la frase «Los pintores de hoy temen a la pintura, la rehúyen» aparece con pequeñas variantes. Curiosas, en cualquier caso, son las referencias al cine y al teatro, artes de las que Miguel Hernández disfrutara y a las que no pudo dedicarse por su pronta muerte. Su viaje a la Unión Soviética es fiel reflejo de esa apetencia por el teatro, y también en la correspondencia a Josefina Manresa manifestó en alguna ocasión su deseo de dedicarse a este género. Cabe observar, asimismo, cómo al poeta, que fue muy de luces y de sombras en su poesía, le sirven estas matizaciones para aplicarlas a otras artes. En cualquier caso, baste reseñar que en aquellos momentos el poeta de Orihuela tenía muy presente la utilidad y especificidad del arte, tal como también se reflejó en la ponencia colectiva que se leyó en Valencia durante el Congreso Internacional de Escritores para la Defensa de la Cultura, y que fue publicada en Hora de España en agosto de I937.

Cerramos el elenco con una reflexión de índole más genérica, y a la vez personal, sobre el arte y sus divisiones geográficas: «Hay pueblos creadores y ipueblos inventores! El de España es un pueblo creador. El de Alemania

6 Juan Cano Ballesta había tenido la oportunidad de ver este manuscrito y anotar solo esta frase. Así lo relata: «En una cuartilla suelta que encontré en los archivos del poeta en agosto de 1985, reproduciendo la misma frase que citábamos antes hallé escrito: "los pintores de hoy temen a la pintura, la rehúyen. Picasso es un ejemplo"» (1993: 135). 
inventor. Odio a los inventores» (22I/I-22). Como se habrá intuido, se trata de una apreciación determinada por el apoyo, o no, de estos países a la causa republicana. Un tipo de análisis similar de estas prosas inéditas, al menos en el tono, lo podemos encontrar en aquellas que bajo el título de «[Arengas y reflexiones sobre España]» incluimos en las Obras completas (Hernández I992: 2240-2246; 2274-2275) y «[Cinco esbozos]» (Hernández I992: 2276-2279).

En un breve período de escritura, Miguel Hernández nos ofreció una obra de elevadísimo alcance en la que, entre los variados temas que abordó, estuvo -aunque fuera sucintamente- el de la reflexión sobre la poesía, tal como demostró en versos, en poemas, en prosas, en teatro. Tal era esta fijeza de cómo abordar y entender la esencia de lo poético que, como se ha podido comprobar, entre las frases de sus borradores incluía muestras que creemos son significativas de cómo el poeta fue percibiendo y concibiendo lo poético a la par que iba aumentando su caudal de lector y una pasión cada día más vívida por la poesía.

\section{Bibliografía}

Alemany Bay, Carmen, «Notas y reflexiones sobre textos, aún inéditos, de Miguel Hernández», en Miguel Hernández/I9Io-20Io. Actas del III Congreso Internacional, tomo I, eds. Carmen Alemany Bay, Miguel Ángel Auladell y José Luis Ferris, Alicante, Instituto Alicantino de Cultura Juan Gil-Albert, 20I2, pp. 2I5-226.

- Miguel Hernández, el desafío de la escritura. El proceso de creación de la poesía hernandiana, Madrid, Visor, 2013.

Aullón de Haro, Pedro, «Las ideas teórico-literarias de Miguel Hernández», en Miguel Hernández, cincuenta años después. Actas del I Congreso Internacional Miguel Hernández, Alicante, Universidad de Alicante/Comisión Homenaje a Miguel Hernández, I993, pp. 259-27I.

—. «La teoría explícita de Miguel Hernández», en Miguel Hernández: tradiciones y vanguardias, eds. Serge Salaün y Javier Pérez, Alicante, Instituto de Cultura Juan Gil-Albert, I996, pp. 8I-84.

Aznar Soler, Manuel, «Miguel Hernández: ética y estética del comunismo», en Miguel Hernández: tradiciones y vanguardias, eds. Serge Salaün y Javier Pérez, Alicante, Instituto de Cultura Juan Gil-Albert, I996, pp. I45-I62.

Cano Ballesta, Juan \& Robert Marrast, Poesía y prosa de guerra y otros textos olvidados, Madrid, Hiperión, 1977.

—. «Miguel Hernández periodista en el frente y narrador épico», Miguel Hernández, cincuenta años después. Actas del I Congreso Internacional, Alicante, Universidad de Alicante/Comisión Homenaje a Miguel Hernández, I993, pp. I23-I38. 
—. «Miguel Hernández: la reflexión del poeta sobre el arte y la guerra», en Miguel Hernández: tradiciones y vanguardias, eds. Serge Salaün y Javier Pérez, Alicante, Instituto de Cultura Juan Gil-Albert, I996, pp. I35-I44.

—. «Miguel Hernández y el debate cultural de los años treinta (El poeta ante el Guernica)», en Presente y futuro de Miguel Hernández. Actas del II Congreso Internacional Miguel Hernández, eds. Juan José Sánchez y Francisco Esteve Ramírez, Orihuela, Fundación Cultural Miguel Hernández, 2004, pp. I2I-I37.

Hernández, Miguel, Obra completa, eds. Agustín Sánchez Vidal, José Carlos Rovira y Carmen Alemany, Madrid, Espasa Calpe, 1992. 
